\title{
Consumo voluntário e ingestão de nutrientes em Forpus coelestis (tuim) alimentados com ração comercial e sementes' ${ }^{1}$
}

\author{
MACHADO, Rodrigo Girata²; FERNANDES, Barbara ${ }^{3}$; OLIVEIRA, Júlia ${ }^{3}$; MORENO, Tatiane ${ }^{4} ;$ ROCHA $^{2}$ \\ Chayane
}

\author{
1Trabalho de Iniciação Científica - UFPR \\ ${ }^{2}$ Graduando de Medicina Veterinária - UFPR, Curitiba - PR, Brasil, Bolsista PIBIC UFPR TN. \\ ${ }^{3}$ Graduanda em Zootecnia, UFPR \\ ${ }^{4}$ Zootecnista, Mestranda do Programa de Pós-graduação em Zootecnia UFPR; \\ ${ }^{5}$ Professora do Departamento de Zootecnia, UFPR. \\ E-mail: rgiraia@gmail.com
}

RESUMO: Avaliou-se consumo voluntário e estimou-se ingestão de nutrientes por Forpus coelestis frente à oferta de diferentes alimentos. Foram distribuídas 21 aves em três tratamentos e sete repetições, T1: Ração extrusada (RE), girassol $(G)$, alpiste $(A)$ e painço $(P)$; T2: $R E+A+P$; T3: RE. Para cada alimento foram determinados teor de matéria seca (MS), proteína bruta (PB), extrato etéreo (EE), matéria mineral $(\mathrm{MM})$, cálcio $(\mathrm{Ca})$, fósforo $(\mathrm{P})$ e energia bruta $(\mathrm{EB})$. Foi estimada a ingestão total (IT) MS, nutrientes (g/dia) e EB (kcal/dia/kg). Não foi verificada diferença $(p>0,05)$ para ITMS entre T1, T2 e T3 $(4,180 ; 3,670$ e 3,750g $\mathrm{MS} /$ ave/dia, respectivamente). Houve diferença para ITPB $(p=0,015)$ e ITEB $(p<0,0001)$ onde T1 apresentou maior ITPB $(0,64 g$ PB/MS/dia $)$ e ITEB (25,18kcal/kg/dia) comparado a T2 e T3 $(047 ; 0,50 \mathrm{~g}$ PB/MS/dia e 15,58; $16,47 \mathrm{kcal} / \mathrm{kg} / \mathrm{dia})$. A ITEE diferiu entre os tratamentos $(p<0,0001)$ onde $\mathrm{T} 1>\mathrm{T} 3>\mathrm{T} 2$ $(0,87 ; 0,39 ; 0,11 \mathrm{~g} \mathrm{EE} / \mathrm{MS} / \mathrm{dia})$. Para ITCa e ITP houve diferença significativa entre os tratamentos $(\mathrm{p}<0,0001)$ sendo T3 $(0,037 \mathrm{~g} \mathrm{Ca/MS} / \mathrm{dia})>\mathrm{T} 1$ e T2 $(0,007 ; 0,008 \mathrm{~g}$ $\mathrm{Ca} / \mathrm{MS} /$ dia) e T2 (0,100g P/MS/dia)>T1 e T3 (0,018 e 0,017g P/MS/dia). Entre T1 o alimento mais ingerido foi $G>A>P>R E(p<0,0001: 2,40 ; 1,14 ; 0,58$ e 0,06 g/ave/dia). Já entre $T 2$ foi $A>P>R E(2,23 ; 1,06 ; 0,38$ g/ave/dia). A presença de alimento palatável fez com que o principal limitador de ingestão fosse 0 enchimento do trato digestório, demonstrando que, possivelmente, essas aves sejam incapazes de balancear sua dieta.

Palavras-chave: dieta monótona; girassol; psitacídeos.

\section{INTRODUÇÃO}

Como consequência do desconhecimento das necessidades nutricionais de psitacídeos em cativeiro, as deficiências nutricionais são as causas mais comuns de doenças, devido ao fato de grande parte dos alimentos comercialmente disponíveis serem à base de misturas de sementes multideficientes. Além disso, os pássaros comem seletivamente, o que pode levar a um desequilíbrio nutricional dos alimentos ingeridos (LUMEIJA et al., 1996).

Devido à necessidade de maiores informações acerca da alimentação de psitacídeos em cativeiro, este estudo teve por objetivo quantificar o consumo voluntário e estimar a ingestão de nutrientes para Forpus coelestis (Tuim) e verificar a capacidade dessas aves em balancear a sua dieta frente a livre oferta de diferentes alimentos. 


\section{MATERIAL E MÉTODOS}

O projeto foi aprovado pelo Comitê de Ética ao Uso de Animais da Universidade Federal do Paraná (certificado 066_2017). Os experimentos foram conduzidos no Laboratório de Criação e Incubação de Animais Silvestres - LACRIAS, da Universidade Federal do Paraná - UFPR.

Foram alojadas individualmente 21 aves adultas em manutenção do gênero Forpus coelestis distribuídas aleatoriamente em três tratamentos com sete repetições cada, totalizando 21 unidades experimentais (UE). Cada UE foi composta por uma gaiola do tipo voadeira (arame galvanizado, 0,60 $\mathrm{x}$ $0,50 \times 0,50 \mathrm{~m}$ - comprimento, largura e altura), que foram mantidas em salas com ambiente fechado em alvenaria. As UE permaneceram alocadas lado a lado em suportes na parede, em sete colunas sobrepostas em três andares. Entre cada UE, havia bandejas coletoras de sobras e desperdício. Cada UE continha dois poleiros de madeira, potes de alimentação idênticos e bebedouros do tipo nipple.

Os alimentos fornecidos foram: alimento completo comercial de manutenção para psitacídeos de pequeno e médio porte (ração extrusada) (RE); semente de girassol $(G)$; semente de alpiste (A); semente de painço (P). Cada tratamento foi estabelecido como segue: T1: RE, G, A e P, T2: RE A e P, e T3: RE. Cada alimento foi fornecido individualmente por comedouro.

Os animais foram pesados ao início e ao término do experimento de forma a acompanhar a variação de peso. Após período de adaptação, o consumo voluntário foi quantificado durante oito dias através da pesagem do fornecimento, sobras e desperdício. Cascas vazias de sementes foram contabilizadas como sobra. O cálculo de consumo foi ajustado para semente descorticada conforme a fórmula: consumo voluntário $=$ fornecimento (sobra + desperdídicio).

Todos os alimentos fornecidos às aves foram analisados no Laboratório de Nutrição Animal da UFPR para determinação dos teores de matéria seca (MS), proteína bruta (PB), extrato etéreo (EE), matéria mineral (MM), cálcio $(\mathrm{Ca})$ e fósforo $(\mathrm{P})$ segundo metodologia descrita pela AOAC (1995). A energia bruta (EB) foi determinada em bomba calorimétrica (Model 1261, Parr Instrument Co., Moline, IL).

Com base no consumo voluntário médio e conhecendo a composição bromatológica de cada item alimentar foi estimada a ingestão de nutrientes (PB, EE, RM, Ca, P e EB) por ave/dia e por quilograma de peso metabólico. Para correção da ingestão de matéria seca e de nutrientes pelas aves, uma amostra de 100 gramas de cada semente ofertada às aves foi manualmente descorticada, o que possibilitou quantificar a proporção entre conteúdo intracelular e cascas, e analisar em laboratório somente o material ingerido pelas aves.

As aves foram distribuídas em delineamento inteiramente casualizado e os dados analisados quanto à normalidade dos resíduos (Teste de Shapiro-Wilk) e homogeneidade das variâncias (Teste de Bartllet). Os dados foram submetidos à análise de variância e, quando significativos, as médias de consumo voluntário, ingestão de nutrientes e coeficiente de digestibilidade foram comparadas pelo teste de Tukey ao nível de $5 \%$ de significância $(P<0,05)$.

\section{RESULTADOS E DISCUSSÃO}

Foi possível observar que a proporção casca/conteúdo intracelular apresentou variação dentre as opções de sementes, sendo 0 valor da 
proporção para G graúdo, G miúdo, A e P 1,$05 ; \quad 0,53 ; \quad 1,94$ e 0,26 respectivamente. Os resultados demonstram a importância da mensuração do consumo voluntário considerando o peso das cascas como material não consumido.

Os resultados da ingestão total (IT) de matéria seca e nutrientes estão apresentados na tabela 1. A ITMS (gramas/ave/dia) não apresentou diferença significativa entre os tratamentos $(p>0,05)$. Para ITPB e ITEB os animais de $\mathrm{T} 1$ obtiveram maior consumo quando comparados à T2 e T3 $(p<0,05)$, com consumo médio de 0,15 g/dia a mais de PB e $9 \mathrm{kcal} / \mathrm{dia}$ de EB. Para ITEE, as aves de T1 consumiram 0,76 e $0,48 \mathrm{~g} /$ dia a mais que T2 e T3, respectivamente $(p<0,0001)$. Já para ITCa as aves de T3 obtiveram maior consumo de $\mathrm{Ca}$ quando comparado a T1 e T2, consumindo em média 0,029 g/dia a mais. Para ITP as aves de T2 apresentaram menor consumo de $P$ quando comparado a T1 e T3, sendo $0,007 \mathrm{~g} / \mathrm{dia}$ a menos. Para todos os tratamentos, a ingestão de alimento ficou acima dos $10 \%$ de PV esperados, o que leva a hipótese que o principal fator regulador de consumo tenha sido a capacidade física do trato digestório das aves.

\begin{tabular}{|c|c|c|c|c|}
\hline & $\mathrm{T} 1$ & $\mathrm{~T} 2$ & T3 & $p$ \\
\hline PV (g) & 32,8 & 34,2 & 35,2 & - \\
\hline Ingestão de MS/PV (\%) & 12,7 & 10,7 & 10,6 & - \\
\hline ITMS (g/ave/dia) & 4,18 & 3,67 & 3,75 & 0,434 \\
\hline ITPB (g de PB/MS/dia) & $0,64^{\mathrm{a}}$ & $0,47^{\circ}$ & $0,50^{\circ}$ & 0,015 \\
\hline ITEE ( $g$ de EE/MS/dia) & $0,87^{a}$ & $0,11^{\mathrm{c}}$ & $0,39^{\circ}$ & $<0,0001$ \\
\hline ITCa ( $\mathrm{g}$ de Ca/MS/dia) & $0,007^{\mathrm{b}}$ & $0,008^{\mathrm{b}}$ & $0,037^{a}$ & $<0,0001$ \\
\hline ITP (g de P/MS/dia) & $0,018^{a}$ & $0,010^{b}$ & $0,017^{\mathrm{a}}$ & 0,0004 \\
\hline ITEB (kcal/kg/dia) & $25,18^{\mathrm{a}}$ & $15,58^{b}$ & $16,47^{\circ}$ & $<0,0001$ \\
\hline
\end{tabular}

Por meio da comparação entre ingestão de itens alimentares dentre um mesmo tratamento (Tabela 2), foi possível verificar que $G$ foi $o$ alimento mais consumido em $\mathrm{T} 1$ seguido por $\mathrm{A}>$
$P>\operatorname{RE}(p<0,0001)$. Para T2 o alimento mais consumido foi $A \quad(p<0,0001)$, seguido por $P>R E$. Nota-se que para ambos os tratamentos o consumo de MS proveniente de sementes foi muito mais significativo do que o advindo de RE, chegando a $98 \%$ e $89 \%$ para T1 e T2 respectivamente. Os resultados nos levam a hipótese de que a presença de um item alimentar altamente preterível, como o caso de $G$ e A, faz com que o animal não consiga regular a sua ingestão de nutrientes.

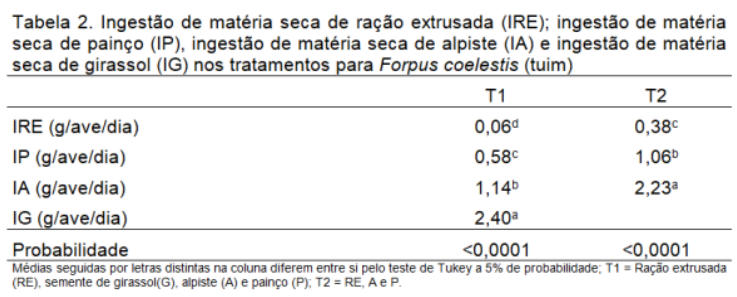

De acordo com recomendações da AAFCO (1998), a ingestão de PB (\%) e $\mathrm{P}(\%)$ pelos indivíduos, atenderam as recomendações mínimas. Entretanto, a exigência mínima de $\mathrm{Ca}$ foi atendida somente pelas aves de T3. Nota-se que as aves de T1 e T2 não foram capazes de ingerir o requerimento mínimo de cálcio. A relação $\mathrm{Ca}$ : $\mathrm{P}$ foi mantida próxima ao máximo recomendado somente para T3. Para T1 e T2 o consumo seletivo de sementes, ocasionou 0 desbalanço entre a ingestão destes minerais. Segundo Ritchie e Harrison \& Harrison (1994), a baixa concentração de cálcio na dieta é capaz de ocasionar decréscimo no aproveitamento de proteínas, gordura, vitamina e minerais, e a devida proporção entre $\mathrm{Ca}$ e $\mathrm{P}$ é necessária para um crescimento adequado e boa manutenção óssea.

Os animais de todos os tratamentos atingiram a estimativa da necessidade energética de psitacídeos adultos para manutenção em gaiola em relação ao peso vivo. No entanto, os animais de $\mathrm{T} 1$ apresentaram consumo 
de energia duas vezes superior as suas necessidades por $G$ possuir elevado teor energético. Segundo Harrison (1998), o excesso de energia proveniente de dietas desbalanceadas leva a distúrbios metabólicos representando risco à saúde dos animais.

Ao final do período experimental, para as aves de $\mathrm{T} 1$ foi observado decréscimo de peso de $1,5 \%$ em relação ao início do experimento. Já para T2 e T3 houve um acréscimo de aproximadamente $1,2 \%$ e $4,6 \%$, respectivamente. Os resultados nos levam a hipótese de que o aproveitamento de nutrientes pelas aves de T1 possa ter sido limitado pela desproporção entre $\mathrm{Ca}$ e $\mathrm{P}$, que atingiu valores críticos para esse tratamento. Além disso, o não atendimento ao requerimento mínimo de $\mathrm{Ca}$ recomendado pela AAFCO (1998) pode ter levado a uma mobilização de reserva óssea para a manutenção da homeostasia. Ainda, os resultados levam a acreditar que os nutrientes presentes na ração extrusada comercial estão mais disponíveis às aves em relação aos provenientes de sementes.

\section{CONCLUSÃO}

A presença de alimentos palatáveis, mas nutricionalmente desbalanceados, como sementes, principalmente o girassol, fez com que o principal fator limitador de ingestão da dieta fosse 0 enchimento do trato digestório, demonstrando que, possivelmente, essas aves, quando mantidas em cativeiro, sejam incapazes de balancear sua dieta no caso de uma oferta livre de sementes. Ainda, uma dieta monótona ou com livre oferta de sementes pode ser prejudicial á saúde da ave devido ao alto teor energético e ao desbalanço na proporção entre cálcio e fósforo. A comparação dos resultados com a literatura existente sugere que existe a necessidade de dar continuidade às pesquisas voltadas para exigências nutricionais se manejo alimentar de Psitacídeos de diferentes espécies.

\section{REFERÊNCIAS}

HARRISON, G.J. Forty-three years of progress in pet bird nutrition. Journal of the American Veterinary Medical Association, v.212, n.8, p.12261230,april 151998.

LUMEIJA, J. T.; ZIJP, N. M. N.; SCHIPPERS, R. The acceptance of a recently introduced extruded parrot food in the Netherlands. Israel Journal of Veterinary Medicine, The Aviv, v. 51, n. 3/4, p. 161-164, 1996.

RITCHIE, HARRISON \& HARRISON. Avian Medicine: Principles and Applications, 1994. Disponível em: http://avianmedicine.net/publication cat/ avian-medicine/ Acesso em 23 de Mar. 2017.

Agradecemos ao apoio da Fundação Araucária e da Coordenação de Aperfeiçoamento de Pessoal de Nível Superior - CAPES na realização do $3^{\circ}$ Workshop de Nutrição de Animais Selvagens.
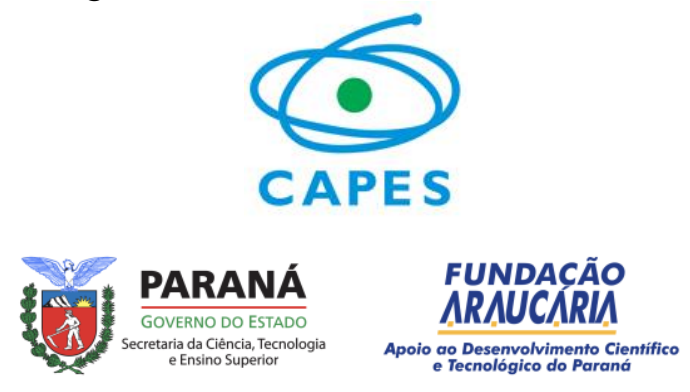